\title{
Neurophysiological evidence for two processing times for visual object identification
}

\author{
Haline E. Schendan ${ }^{\mathrm{a}, *}$, Marta Kutas ${ }^{\mathrm{b}}$ \\ a Department of Psychology, Boston University, 648 Beacon Street, Boston, MA 02215, USA \\ ${ }^{\mathrm{b}}$ Department of Cognitive Science, University of California, San Diego, CA, USA
}

Received 24 March 2000; received in revised form 29 June 2001; accepted 19 July 2001

\begin{abstract}
Event-related brain potentials (ERPs) were recorded to fragmented pictures of objects that were named correctly or were not to investigate the time course of visual object identification. The first ERP difference distinguishing identified from unidentified pictures estimates the upper limit of the time by which human brain regions have begun to activate long-term memory (LTM) representations specifying the identity of a visual object. Data from 15 young adults indicate that this time varies with the extent to which object parts are recoverable from the visual input, being $\sim 200 \mathrm{~ms}$ earlier with recoverable than unrecoverable parts. Successful identification is evident by $\sim 300 \mathrm{~ms}$ when object parts and overall structural configuration are readily recoverable but not until $\sim 550 \mathrm{~ms}$ when object parts are difficult or impossible to recover (i.e. too poorly specified by the available contours to be recovered). In both cases, successful identification is associated with greater relative positivity. However, unidentified recoverable pictures are associated with an enhanced frontal negativity (N350), linked to object matching operations, not seen for non-recoverable pictures. Taken together, these results implicate two distinct processing sequences in the successful identification of visual objects. (C) 2002 Elsevier Science Ltd. All rights reserved.
\end{abstract}

Keywords: Visual perception; Part recoverability; Picture fragment completion; Late positive complex; Frontal negativity; Event-related potential

\section{Introduction}

Visual object identification is an act of categorization variously referred to as "object model selection" in computational vision (e.g. [59]) or a "structural description system" in psychology (e.g. [21,43]). It occurs once perceptual processing has advanced sufficiently and long-term memory representations resembling the highly processed percept are activated. These representations store information about the perceptual structure of classes of known (i.e. previously familiarized) objects and are used to determine the particular category (e.g. dogs or cars) to which an object belongs. This higher-order categorization can in turn activate associated knowledge (e.g. a function or name) in the same or another neural system thereby enabling response-related processes, such as naming.

The present study investigated the time course of successful visual identification, focusing on the moment when the correct object model is selected from long-term memory. To that end, event-related potentials (ERPs) to fragmented line drawings that are similar at the level of the retina and percep-

\footnotetext{
* Corresponding author. Tel.: +1-617-358-2037; fax: +1-617-353-9609/1424

E-mail address: schendan@bu.edu (H.E. Schendan).
}

tually were compared during successful versus failed object identification. ERPs are a non-invasive tool for assessing the timing and functional characteristics of the neurophysiological events underlying cognition. The latency when ERPs to identified and unidentified images first diverge indicates the maximum amount of processing time needed by the human brain to begin visual object identification.

Two prior ERP studies comparing successful and failed identification reported divergence times that differed by a few $100 \mathrm{~ms}$ (600 ms [55] versus less than $300 \mathrm{~ms}$ [37]). Stuss et al. [55] showed people fragmented line drawings of objects at four levels of completeness and found a broadly-distributed late positive complex (LPC) that diverged as a function of naming accuracy by $550-650 \mathrm{~ms}$. Pietrowsky et al. [37] replicated the LPC finding but also observed an earlier effect; identified landscapes first differed from unidentified and scrambled scenes by $\sim 250-300 \mathrm{~ms}$ in a frontal negativity peaking between 325 and $400 \mathrm{~ms}$ (N350) $[37,45,48]$. Presence or absence of the frontal N350, thus, distinguishes the timing of visual identification between these two studies.

Here, we assess two potential explanations for these discrepant results: stimulus factors and memory factors. Regarding stimulus factors, we hypothesized that identification occurs during an earlier phase of object model selection, 


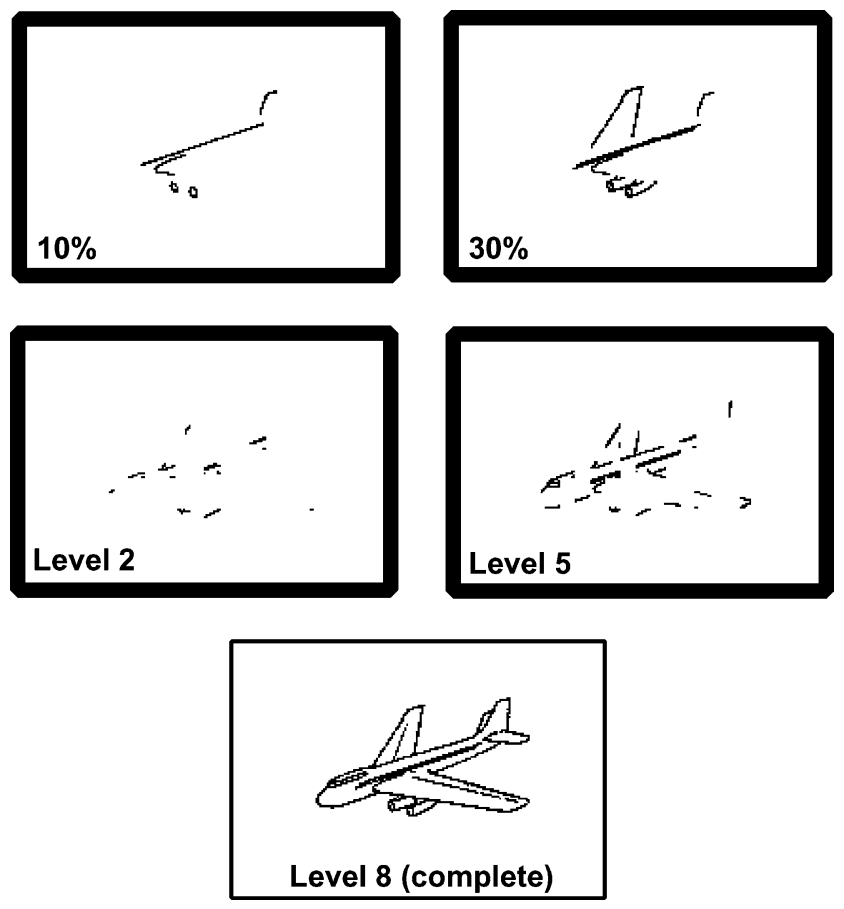

Fig. 1. Recoverable (Levels 5 and 8 ) versus non-recoverable (10, 30\%, Level 2) pictures. Top panels show our adaptations of a [53] picture (bottom panel) into examples of fragmented pictures like the 10 and $30 \%$ complete ones used by Stuss et al. [55]. Both Stuss et al. [55] types (top) have missing parts and others that are "non-recoverable": most remaining contours cannot be connected (e.g. by collinearity) to recover incomplete parts. Middle panels show examples of Levels 2 and 5 fragmented pictures. At Level 2, the paucity of available contour, even if perceptually connected, cannot easily reconstruct identifiable parts: parts are non-recoverable. In contrast, at Level 5, sufficient contour is shown to enable collinear lines to be connected perceptually into diagnostic parts (e.g. fuselage and wings): parts are "recoverable".

indexed by the N350, whenever images have most (if not all) of their parts visible or recoverable, as in Pietrowsky et al. [37], than when their parts are entirely missing, or not recoverable from the visible contours, as in Stuss et al. [55] (Fig. 1); successful object identification from non-recoverable parts is first seen in the LPC. In other words, identification may succeed even when information entering the object model selection stage (N350) is insufficient, but it does so later (LPC), after additional neural processing, compared to when information is sufficient.

Regarding memory, various short- and long-term episodic memory processes are known to affect identification time and naming accuracy (e.g. [3,11,15,31,51,61]); both prior studies included repeated stimuli but in different ways. In Stuss et al. [55], the identification processes were subject to episodic long-term memory(LTM) influences since participants had seen complete versions of the fragmented drawings along with their names before the actual ERP recording. This can be problematic given the known similarity in the time course and ERP componentry associated with identification and some LTM effects. For instance, relative to new ones, repeated items can evoke more posterior positivity (LPC) $300-900 \mathrm{~ms}[34,35,42]$. In principle, then, if repetition positivity is larger for unidentified than identified objects, an ERP repetition effect can overlap and thereby eliminate an N350 identification effect. Pietrowsky et al. [37] repeated each scene successively until it was identified. Immediate repetition engages working memory systems and elicits a repetition positivity that begins and peaks at an earlier latency than for repetitions at longer delays $[3,33,47]$. The earlier positivity to identified than unidentified objects in Pietrowsky et al. [37] may reflect availability in working memory of information about the previously unidentified yet visually similar image.

To assess how stimulus properties (i.e. structural visibility and recoverability) and memory (working memory, LTM) alter the timing of visual object identification, these factors were varied across blocks (Fig. 2). To examine the effect of part recoverability, we used fragmented pictures with parts that were either (a) missing and non-recoverable or (b) visible and recoverable. Both appeared in Block 1; only non-recoverable images appeared in Block 2 (Level 2 ); only recoverable images appeared in Block 3 (Level 5). If it is non-recoverability of parts that slows identification, ERPs to identified and unidentified objects should diverge later $(\sim 600 \mathrm{~ms})$ for the non-recoverable images in Blocks 2 (and 1) than for the recoverable ones in Blocks 3 (and 1) which could diverge as early as $300 \mathrm{~ms}$. To assess the effects of working memory and LTM, respectively, objects were either new or repeated at short (Block 1) or long (Blocks 2 and 3) delays. We hypothesized that the availability in working memory of a previously unidentified scene resembling current input led to the early latency of the Pietrowsky et al. [37] identification effects. Likewise, we hypothesized that prior exposure to the pictures and their names had engaged LTM and so spuriously prolonged the first ERP sign of identification in Stuss et al. [55]. If these hypotheses are true, identification effects should be earliest for items in Block 1, speeded by working memory processes and, in Blocks $2-3$, intermediate for new objects, subject to neither working memory nor LTM factors, and the latest for repeated items, subject to only LTM processes.

\section{Method}

\subsection{Materials}

On a monitor of an IBM-compatible personal computer, 140 digitized pictures of objects at six fragmentation levels (2-7) were shown in black against a white background. Fragmented versions were from the Snodgrass and Corwin [50] set, or the first author used software [52] to fragment other pictures in the Snodgrass and Vanderwart [53] set. For practice, eight objects were reserved. To counterbalance stimuli across conditions, two sets of 70 objects were 


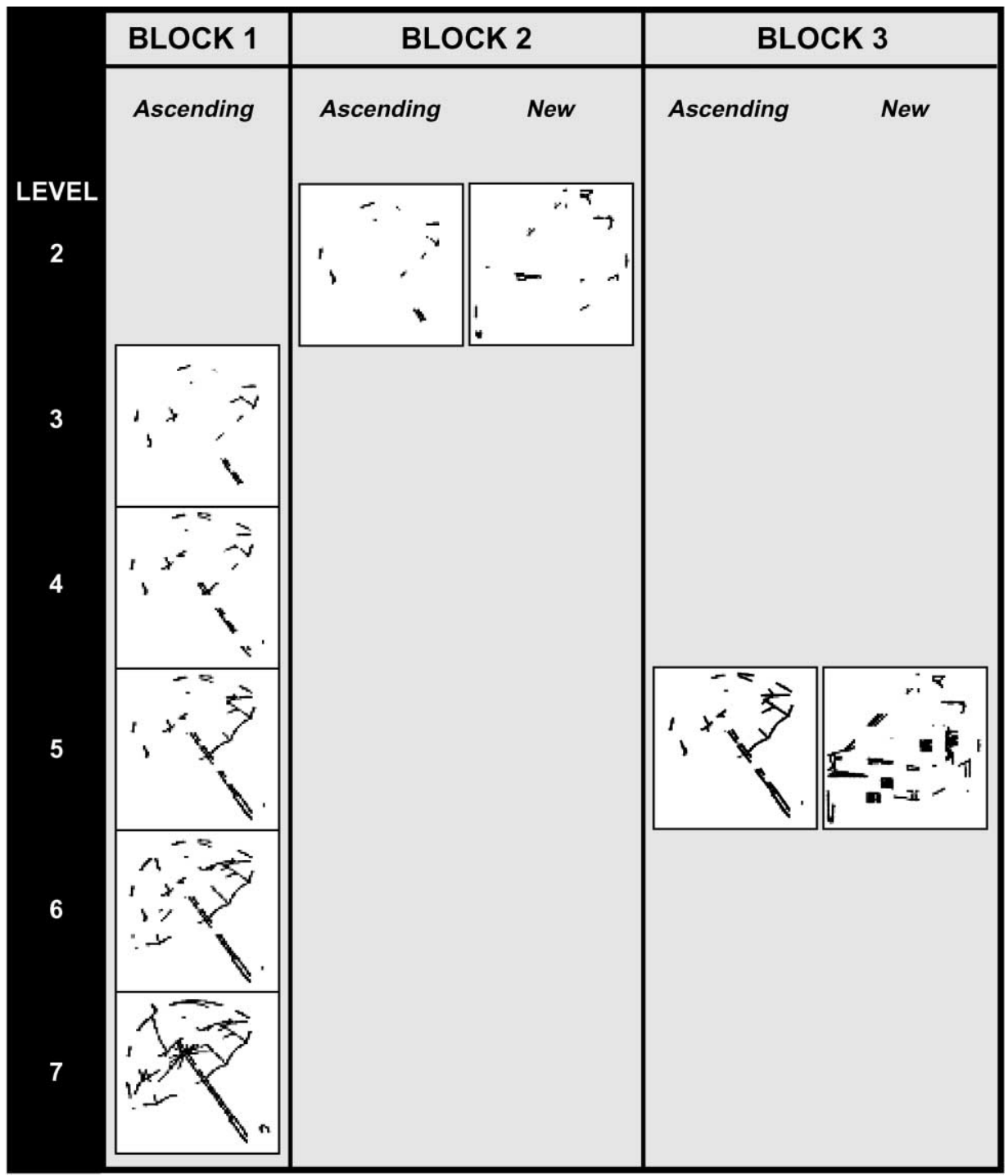

Fig. 2. Stimulus factors (i.e. levels) and memory factors varied across three blocks. In Block 1, people saw each object at five levels of fragmentation in an ascending sequence from the least complete (Level 3) to the most complete (Level 7) picture. The first presentation of objects in the ascending condition occurred in Block 1. In subsequent Blocks 2 and 3, each object was shown at only a single level of fragmentation. In Block 2, objects were seen at highly fragmented Level 2 (a level not seen before) with 12\% contour but recoverability akin to 10 and $30 \%$ complete pictures of Stuss et al. [55]. In Block 3, objects were seen at moderately fragmented Level 5 with 34\% contour which is about equal to 30\% versions of Stuss et al. [55]). Note that these pictures also pit percent contour against recoverability as an explanation of results. In Block 2, objects either were repeated from Block 1 (ascending condition) or had not been seen before (new condition). In Block 3, all objects were repeated; objects had either been shown twice before in Blocks 1 and 2 (ascending condition) or once before (as formerly new objects) in Block 2 (new condition).

matched according to all picture norms [50,53]. Set assignment to conditions was counterbalanced across individuals. The presentation order of objects was randomized, avoiding nearby semantic associates, and differed for each block. Within each block, however, the order of each object was the same.

\subsection{Design and procedure}

\subsubsection{Electrophysiological recording}

After electrode application, people sat at $80 \mathrm{~cm}$ from a monitor within a sound-attenuating chamber. Tin electrodes recorded electroencephalographic (EEG) activity from 19 scalp sites of the International 10-20 System (Fp1, Fp2, F3, F4, F7, F8, C3, C4, T3, T4, T5, T6, P3, P4, O1, O2, $\mathrm{Fz}, \mathrm{Cz}, \mathrm{Pz}$ ) that were embedded in an elastic cap and from a right mastoid site and an electrode under the right eye to monitor blinks. These recordings were referenced to an electrode over the left mastoid. Electrodes placed lateral to each eye were referenced to each other to monitor horizontal eye movements. Electrooculographic recordings were used to eliminate trials contaminated with ocular artifacts. EEG was recorded with a bandpass of $0.01-100 \mathrm{~Hz}$ and digitized at $250 \mathrm{~Hz}$. 


\subsubsection{General}

The three blocks differed in the fragmentation levels shown and stimulus repetition (Fig. 2). People received written and oral instructions and practice before each block (after a 5-10 min rest) and were asked to withhold eye, or other, movements while the pictures were shown. Each picture appeared for $1150 \mathrm{~ms}$. Each trial began with a fixation mark ("+") and ended with a question mark, each shown for $1150 \mathrm{~ms}$. Offset and onset of stimuli (pictures, marks) were separated by $50 \mathrm{~ms}$.

\subsubsection{Block 1}

To examine the role of working memory, each of 70 new objects was presented in a sequence of five fragmented pictures (Levels 3-7): "ascending method of limits" procedure [51] for the "ascending" condition. Participants pressed a button (dominant hand) as soon as they were sure they had correctly identified the object; when unsure or having no idea, they did not press the button (i.e. no-go). Participants were asked to attend equally to each fragment level in the sequence, even after identification. After naming the object at the end of the sequence, people also reported any errors they might have made (e.g. pressed identification button too soon or late).

\subsubsection{Blocks 2 and 3}

Objects were shown at one fragmentation level: Level 2 (non-recoverable) in Block 2, or Level 5 (recoverable) in Block 3. Participants named each object after a question mark appeared and rated their confidence (non-dominant hand): very sure (forefinger), sure (middle), unsure (ring), very unsure (little finger). To evaluate the LTM hypothesis, in Block 2, all 70 "ascending" objects from Block 1 were repeated and intermixed randomly with 70 "new" objects, and, in Block 3, both ascending and new objects were repeated, albeit at a different fragmentation level. Participants were not told that objects would repeat but were told in Block 3 that they would be easier to identify.

\subsubsection{Data analyses}

"Identified" objects were those given a Snodgrass and Vanderwart [53] name. ERPs were computed from $200 \mathrm{~ms}$ before picture onset to $820 \mathrm{~ms}$ after, referenced to the numerical average of left and right mastoids, unfiltered in Block 1 and low pass filtered at $30 \mathrm{~Hz}$ in Blocks 2 and 3 to facilitate application of blink correction software to data from eight participants. The number of trials per condition was typically $\sim 30$ (minimum of six trials per condition was required for a reliable ERP average). One ANOVA covered midline (Mid.) and another lateral (Lat.) electrodes to assess hemispheric asymmetry. ANOVAs included a between-person factor of list and within-person factors of electrode site, hemispherefor lateral analyses, identification (identified, unidentified), repetition (ascending, new) and/or block. Statistics reflect the Huynh-Feldt correction for the assumption of sphericity. Mean amplitude was measured from 300 to $400 \mathrm{~ms}$ for the N350, 500-800 ms for the LPC, and $400-500 \mathrm{~ms}$ for the time in-between. Bonferroni procedure computed each contrast alpha as family-wise error rate $(0.05)$ divided by number of contrasts associated with a single source of variance. Because a crucial issue of interest was how early identification effects begin, onset latency was investigated for the most important identification contrasts, as advocated by Picton et al. [36]. Point-by-point statistics were done on the appropriate difference waves (identified-unidentified) for each site within the time period when identification effects were reliable $[1,41]$. Onset latency was defined as the time when 15 or more consecutive points differed reliably from zero (with list factor).

To evaluate whether the scalp topography of two effects differs, the shapes of their scalp distributions were compared using ANOVAs on the amplitude of identification difference (identified-unidentified) waves after vector scaling normalization [30]. If two scalp distributions differ in shape, the configurations of their neural generators must differ [54]. In ANOVAs, differences in scalp distribution shape are captured in condition $\times$ site interactions; amplitude normalization is needed because identical neural configurations, if activated to different degrees, can produce spurious condition $\times$ site interactions. Distinct scalp distribution shapes indicate one or more neural generator(s) are activated (a) differentially between conditions or (b) in one but not the other condition. A within-person factor of time tested shape across times. To increase statistical power, all electrodes were analyzed together.

\subsection{Participants}

Nineteen University of California, San Diego students/staff, naïve about the research volunteered for US\$ $5.00 / \mathrm{hr}$. Data of 15 were analyzed; the 4 excluded had too many artifacts or strabismus $(n=1)$.

\section{Results}

Procedural differences between Block 1 and Blocks 2-3 precluded their direct comparison.

\subsection{Block 1}

For objects named correctly, ERPs upon initial identification (as indicated by a button press) were compared to ERPs for the preceding unidentified fragments. The identification factor had three levels: (a) "identified" (\# trials: $M=23$, range 6-39), and, for "unidentified" pictures; (b) "1-before" (fragment level immediately before identification; \# trials: $M=37$, range 20-50), and (c) "2-3-before" (fragments preceding the 1-before fragments; \# trials: $M=$ 48, range 29-88). Analyses were limited to ERPs for (the largely recoverable) fragment Levels 4 and 5 at which most objects were identified; while this controlled fragment level 


\section{IDENTIFICATION EFFECT}

Levels 4 and 5 (Block 1)
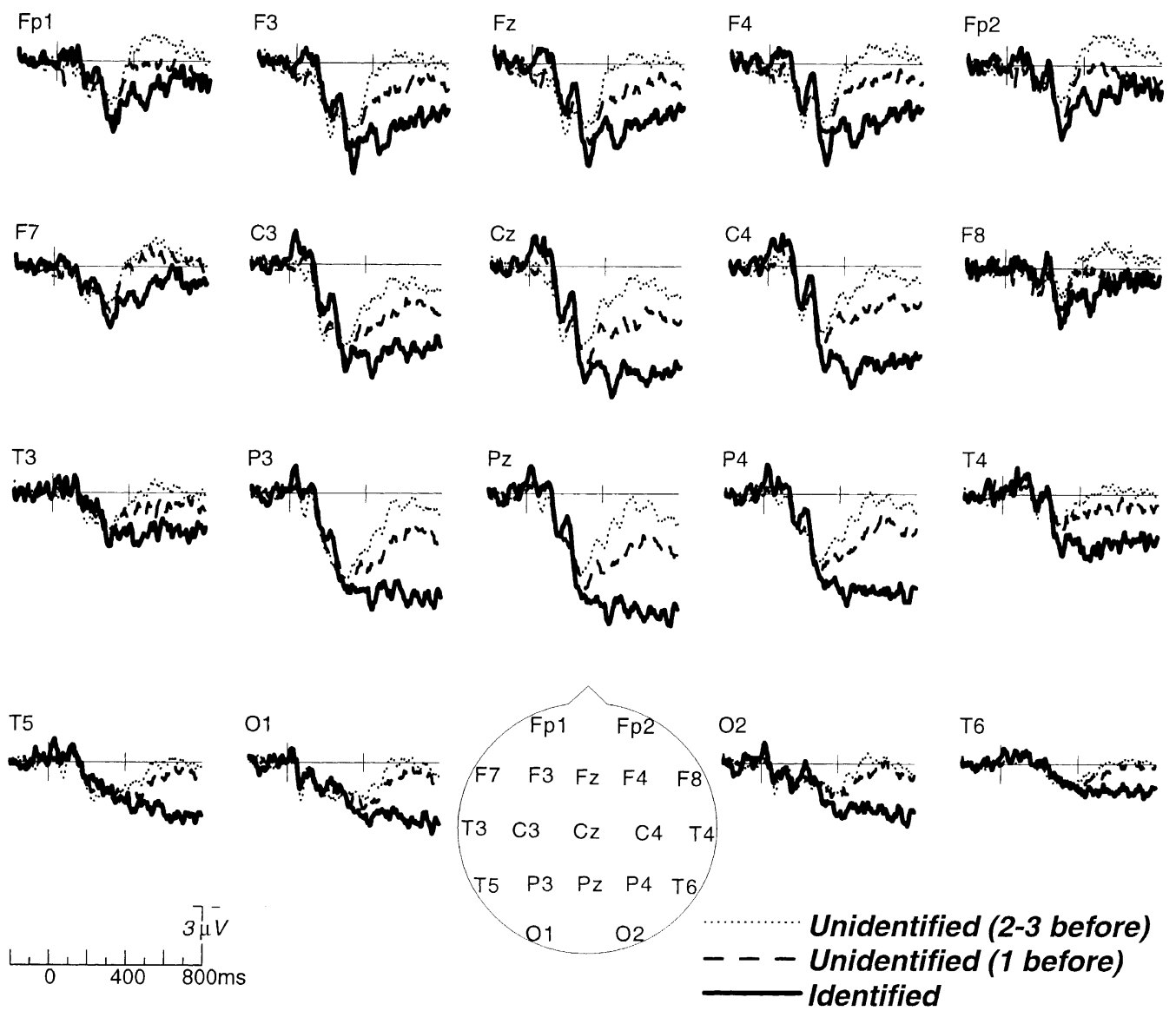

Fig. 3. Grand average ERP waveforms to identified and unidentified fragmented pictures (Levels 4 and 5 ) of each object in Block 1 are shown for 800 ms after stimulus onset with a $200 \mathrm{~ms}$ pre-stimulus baseline (filtered low pass $40 \mathrm{~Hz}$ ). ERPs to fragments where objects were identified showed much more positivity by $300 \mathrm{~ms}$ than those to unidentified fragments (1 or 2-3 fragments before identification).

between conditions, it precluded contrasts of recoverable versus non-recoverable images.

\subsubsection{Identified versus all unidentified}

Identified images evoked more positivity than unidentified ones over most sites (Fig. 3). An omnibus ANOVA with all conditions revealed differences between identified and both unidentified (1-before versus 2-3-before) trials during the $\mathrm{N} 350$; from 300 to $400 \mathrm{~ms}$, reliable main effects of identification, Lat. $F(2,24)=9.66, P=0.0008$, epsilon $(\varepsilon)=1$, Mid. $F(2,24)=9.86, P=0.0008, \varepsilon=1$, interacted with site, Lat. $F(14,168)=2.53, P=0.0378, \varepsilon=0.3702$. The main effects continued through the LPC: 400-500 ms, Lat. $F=16.30, P<0.0001, \varepsilon=0.9454$, Mid. $F=17.73$, $P<0.0001, \varepsilon=0.8373$; LPC $(500-800 \mathrm{~ms})$, Lat. $F=$ 18.54, $P<0.0001, \varepsilon=0.8870$, Mid. $F=29.17, P<$ $0.0001, \varepsilon=0.8497$, and interacted with site: $400-500 \mathrm{~ms}$, Lat. $F=3.48, P=0.0080, \varepsilon=0.3524$; LPC Lat. $F=$ 4.42, $P=0.0040, \varepsilon=0.2876$, Mid. $F(4,48)=3.72, P=$
$0.0369, \varepsilon=0.5885$, and site $\times$ hemisphere: $400-500 \mathrm{~ms}$ $F(14,168)=2.03, P=0.0429, \varepsilon=0.6492$; LPC $F=$ 2.93, $P=0.0126, \varepsilon=0.4541$. At all times, main site effects were reliable, Lat. $F_{\mathrm{S}}(7,84)>8.6, P \mathrm{~S}<0.005, \varepsilon \mathrm{S}>$ 0.32 , Mid. $F \mathrm{~s}(2,24) \geq 3.48, P \mathrm{~s}<0.05, \varepsilon \mathrm{s}>0.81$.

\subsubsection{Identified versus unidentified (1-before; 2-3-before separately)}

ERPs to identified fragments were also contrasted separately with the preceding unidentified fragment level ERPs ( $\alpha=0.025$ ). We reasoned that since participants only had $1200 \mathrm{~ms}$ to respond per fragment, ERPs to the fragment level just before identification (i.e. 1-before) might on occasion include processes associated with successful identification, whereas those to earlier unidentified fragments (i.e. 2-3-before) were unlikely to and, thus, would better reflect failed identification. Consistent with this, ERPs to identified objects showed an earlier $(\sim 300 \mathrm{~ms})$ and larger divergence when compared to unidentified fragments at 
levels 2-3-before than 1-before identification. Compared to 1-before, main identification effects were reliable from 400 to $500 \mathrm{~ms}$, Lat. $F(1,12)=8.53, P=0.0128$, Mid. $F(1,12)=7.94, P=0.0155$, and from 500 to $800 \mathrm{~ms}$, Lat. $F=10.78, P=0.0065$, Mid. $F=18.02, P=0.0011$, and interacted with site, Lat. $F(7,84)=4.38, P=0.0230$, $\varepsilon=0.3096$. Main site effects were reliable at these times, Lat. $F \mathrm{~s}(7,84)>8, P \mathrm{~s}<0.005, \varepsilon \mathrm{s}>0.33$, Mid. $F \mathrm{~s}(2,24)>$ $5.5, P \mathrm{~s}<0.025, \varepsilon \mathrm{s}>0.8$. Compared to 2-3-before, main identification effects were reliable earlier by the N350, $300-400 \mathrm{~ms}$, Lat. $F(1,12)=17.75, P=0.0012$, Mid. $F(1,12)=16.47, P=0.0016$, and interacted with site, Lat. $F(7,84)=4.92, P=0.0019, \varepsilon=0.6328$. Main identification effects were also reliable from 400 to $500 \mathrm{~ms}$, Lat. $F=27.95, P=0.0002$, Mid. $F=27.87, P=0.0002$, and during the LPC, Lat. $F=28.00, P=0.0002$, Mid. $F=39.08, P<0.0001$, and interacted with lateral sites:
400-500 ms $F=5.96, P=0.0023, \varepsilon=0.3903$; LPC $F=5.44, P=0.0099, \varepsilon=0.3419$, and, for the LPC, also site $\times$ hemisphere, $F(14,168)=3.09, P=0.0156$, $\varepsilon=0.6772$. Main site effects were reliable at all times, Lat. $F \mathrm{~s}>6.5, P \mathrm{~s}<0.005, \varepsilon \mathrm{s}>0.3$, Mid. $F \mathrm{~s}(2,24)>5.3$, $P \mathrm{~s}<0.025, \varepsilon \mathrm{s}>0.8$, except midline $300-400 \mathrm{~ms}$.

\subsubsection{Onset latency}

Point-by-point $F$-tests ( $\alpha=0.05$ for one Block 1 analysis) on ERPs to identified minus unidentified (2-3-before) fragments from 300 to $400 \mathrm{~ms}$ estimated the earliest N350 identification effects at $300 \mathrm{~ms}$ for frontocentral sites (F4, C4).

\subsection{Block 2 versus Block 3}

Identification and LTM repetition effects were assessed separately because there were too few identified new

\section{IDENTIFICATION EFFECT Level 2 (Block 2)}
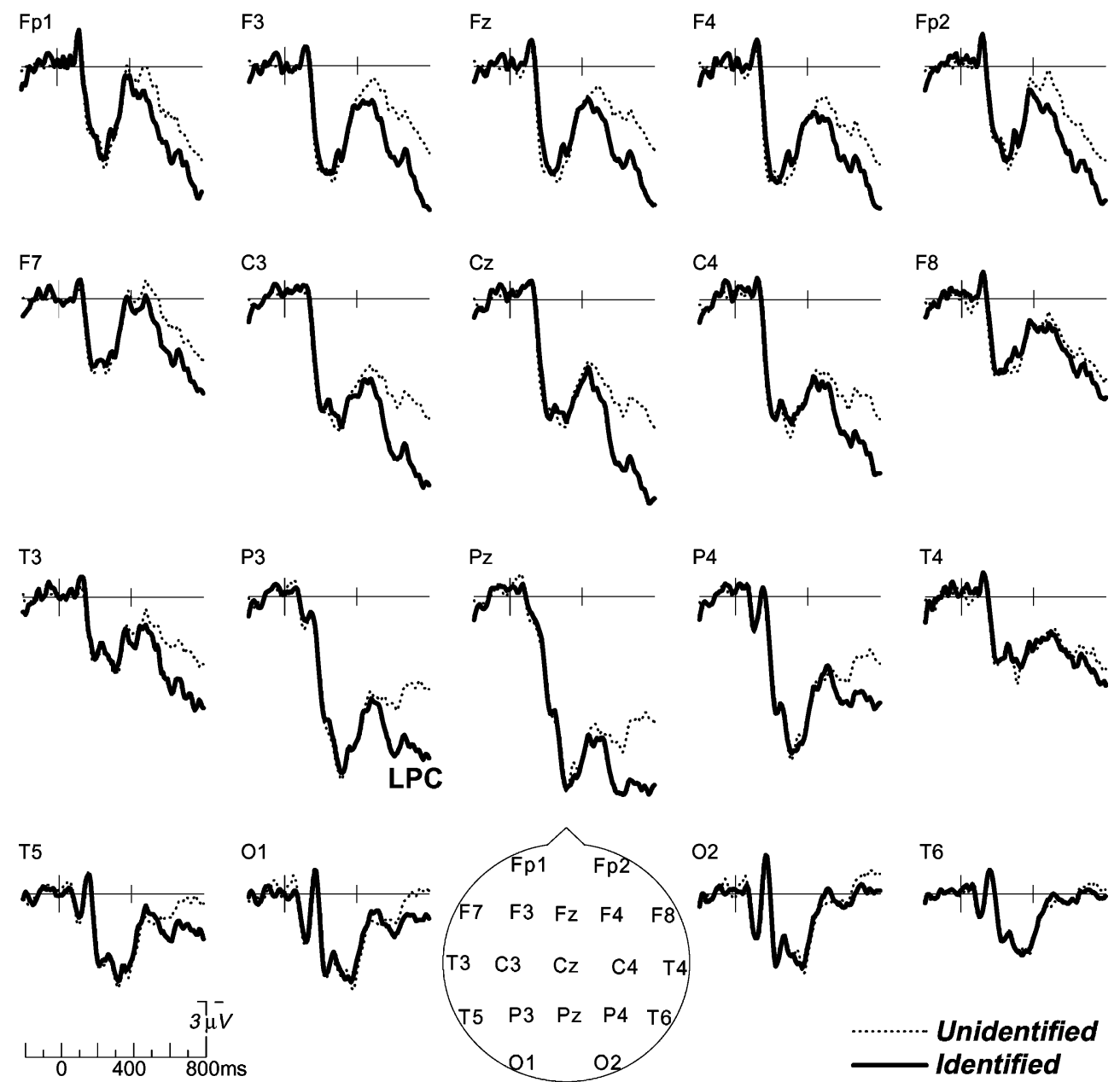

T6

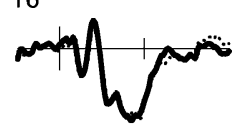

Unidentified

Identified

Fig. 4. Grand average ERP waveforms in Block 2 to identified and unidentified fragments in the ascending condition are shown for $800 \mathrm{~ms}$ after stimulus onset with a $200 \mathrm{~ms}$ pre-stimulus baseline (filtered low pass $40 \mathrm{~Hz}$ ). ERPs to unidentified objects are collapsed across guess and no idea responses. By $544 \mathrm{~ms}$, ERPs to identified and unidentified objects differed reliably. 
objects at Level 2 (Block 2) and unidentified objects at Level 5 (Block 3). An omnibus ANOVA with identification and block factors compared the ascending condition in Block 2 for identified (\# trials: $M=23$, range 13-35) and unidentified objects (\# trials: $M=36$, range 23-46) versus the new condition in Block 3 for identified (\# trials: $M=37$, range 29-45) and unidentified objects (\# trials: $M=18$, range 10-26); the primary factor of interest was identification. As the block factor was confounded with repetition, the latter was assessed in separate ANOVAs within each block (i.e. held constant). For Block 3, identification analyses were limited to new objects that had not been identified in Block 2 to minimize repetition effects; unidentified objects produce little or no priming $[6,7,51]$.

\subsubsection{Omnibus}

Identified objects evoked greater positivity than unidentified ones in both Block 2 (Fig. 4) and Block 3 (Fig. 5) but at different times and modulating different ERP components. An early identification effect was seen around the time of the N350 over frontal sites (Fig. 6): ERPs to unidentified Level 5 fragments had larger N350s than either identified Level 5 pictures (Block 3) or any Level 2 picture (Block 2). Later LPC identification effects were similar for all fragments (Fig. 6). N350 identification effects differed between blocks. From 300 to $400 \mathrm{~ms}$, the identification $\times$ block interaction was reliable at lateral sites, $F(1,12)=5.31, P=$ 0.0399 , and interacted marginally with site $\times$ hemisphere, $F(7,84)=2.18, P=0.0543, \varepsilon=0.8698$; main identification effects were marginal, Lat. $F(1,12)=3.52, P=$

\section{IDENTIFICATION EFFECT \\ Level 5 (Block 3)}
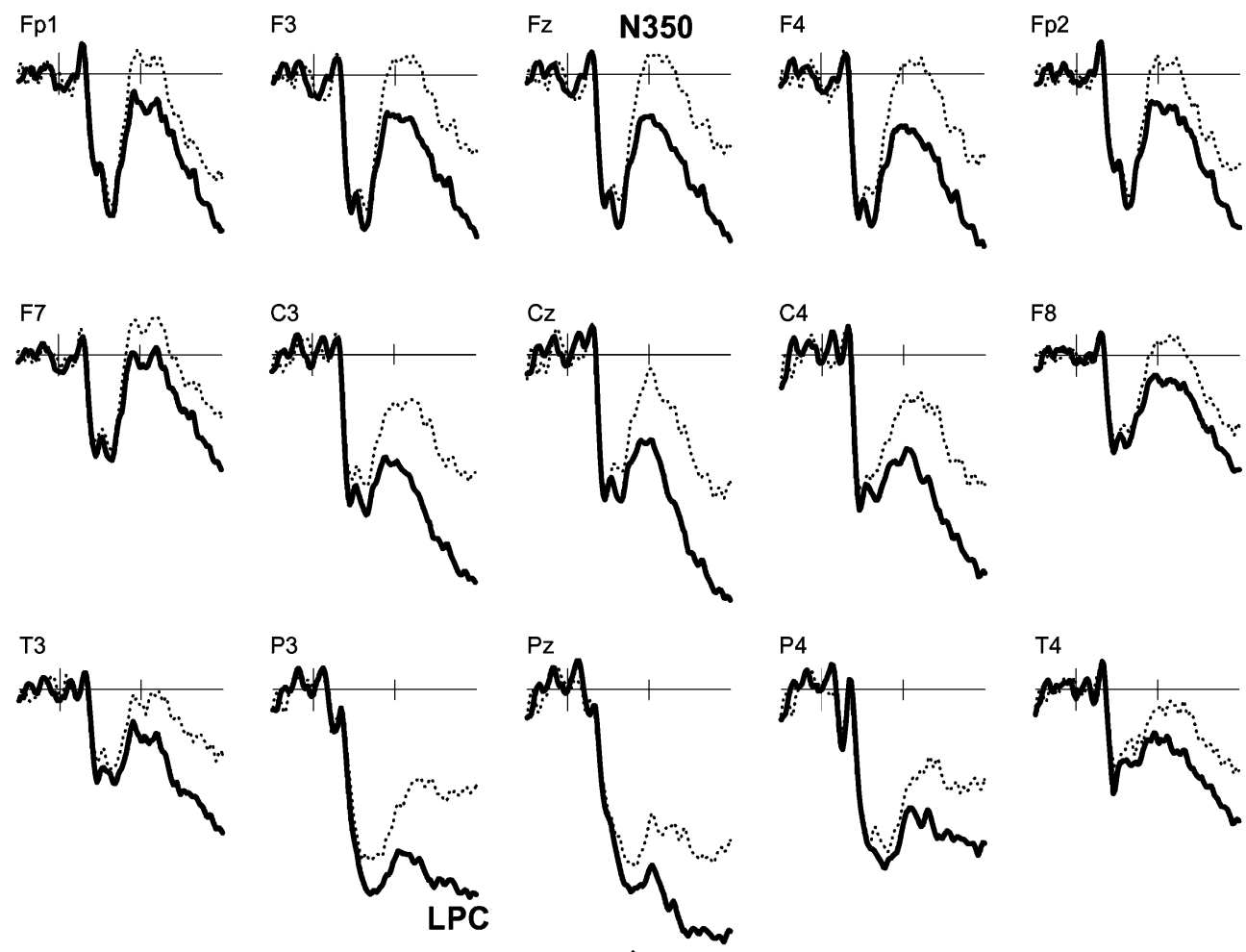

T4
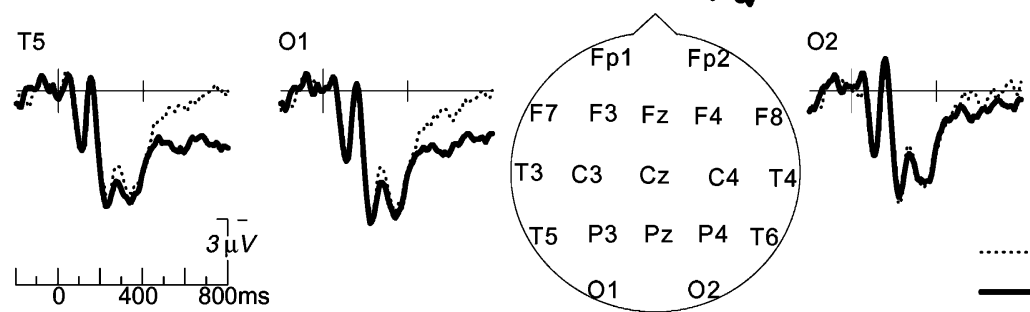

T6

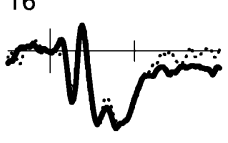

Fig. 5. Grand average ERP waveforms in Block 3 to identified and unidentified fragments in the new condition are shown for $800 \mathrm{~ms}$ after stimulus onset with a $200 \mathrm{~ms}$ pre-stimulus baseline (filtered low pass $40 \mathrm{~Hz}$ ). ERPs to unidentified objects are collapsed across guess and no idea responses. Within $312-336 \mathrm{~ms}$, ERPs to identified and unidentified objects differed reliably, especially frontally, modulating an N350. In particular, the frontal N350 is larger to unidentified than identified recoverable pictures. Later, after $500 \mathrm{~ms}$, the LPC is larger to identified than unidentified objects. 


\section{IDENTIFICATION EFFECTS (Early N350 vs. Late LPC)}

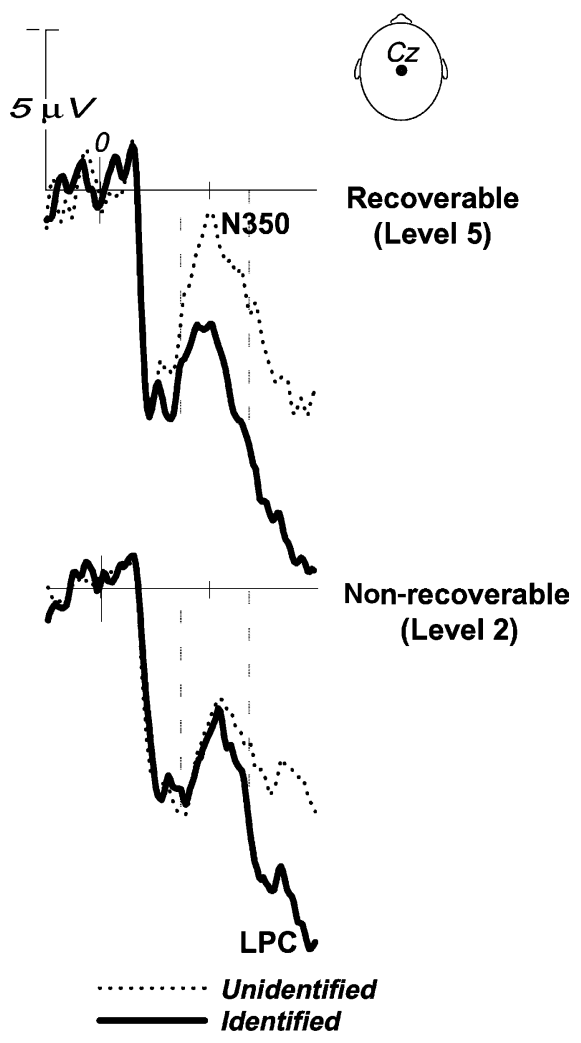

Fig. 6. Grand average ERP waveforms to identified and unidentified fragmented pictures in the ascending condition of Level 2 (Block 2) versus new condition of Level 5 (Block 3) are shown for $800 \mathrm{~ms}$ after stimulus onset with a $200 \mathrm{~ms}$ pre-stimulus baseline (site $\mathrm{Cz}$; dashes delimit 300 and $550 \mathrm{~ms}$ times; filtered low pass $40 \mathrm{~Hz}$ ). ERPs to unidentified fragments are collapsed across guess and no idea responses. The time course of ERP differences between identified and unidentified objects in non-recoverable (Level 2) versus recoverable (Level 5) pictures reveals two processing sequences for visual object identification. The N350 marks the onset of early identification effects for recoverable pictures, whereas the LPC marks late identification effects for any kind of visual image, non-recoverable or otherwise.

0.0853, Mid. $F(1,12)=4.59, P=0.0533$. Only from 300 to $400 \mathrm{~ms}$ did ERPs differ generally between Blocks 2 and 3. Main block effects were reliable at midline sites, $F(1,12)=5.68, P=0.0346$, and block by lateral site interactions were marginal, $F(7,84)=3.09, P=0.0608, \varepsilon=$ 0.3435 . From 400 to $500 \mathrm{~ms}$, the identification $\times$ block interaction was still reliable, Lat. $F=5.19, P=0.0419$, Mid. $F=5.32, P=0.0398$, and now interacted reliably with site $\times$ hemisphere, Lat. $F(7,84)=2.90, P=0.0136, \varepsilon=$ 0.8824 ; in contrast to the N350, main block effects, $F \mathrm{~s}<1$, $P$ s $>0.44$, and block $\times$ site interactions, $F \mathrm{~s}<1.7, P$ s $>$ 0.22 , were not reliable; main identification effects were reliable, Lat. $F=14.75, P=0.0023$, Mid. $F=20.20, P=$ 0.0007 , and interacted with lateral site, $F(7,84)=3.93$, $P=0.0355, \varepsilon=0.2500$. In contrast, later, from 500 to
$800 \mathrm{~ms}$, LPC identification effects were indistinguishable between blocks; main identification effects were reliable, Lat. $F=28.31, P=0.0002$, Mid. $F=33.62, P=0.0001$, interacted reliably with lateral site, $F=8.48, P=0.0002$, $\varepsilon=0.41$, hemisphere, $F(1,12)=10.12, P=0.0079$, and site $\times$ hemisphere, $F(7,84)=4.06, P=0.0063, \varepsilon=0.591$. Main site effects were reliable at all times, Lat. $F \mathrm{~s}(7,84)>$ 5.8, $P \mathrm{~s}<0.005, \varepsilon \mathrm{s}>0.3$, Mid. $F \mathrm{~s}(2,24)>8, P \mathrm{~s}<$ $0.005, \varepsilon s>0.78$, and interacted with hemisphere from 300 to $400 \mathrm{~ms}, F(7,84)=4.46, P=0.0094, \varepsilon=0.4145$. In sum, identification effects differed between Blocks 2 and 3 only early on between 300 and $500 \mathrm{~ms}$ during the frontal N350.

\subsubsection{Level 2 unidentified versus Level 5 identified}

Besides two identification contrasts within Block 2 or 3 , the next three contrasts were between blocks $(\alpha=0.025$, block $\times$ identification interaction is the source of variance for the next two contrasts). ERPs to unidentified ascending Level 2 versus identified new Level 5 fragments differed only during the LPC. From 500 to $800 \mathrm{~ms}$, main effects of condition were reliable, Lat. $F(1,12)=15.79, P=0.0018$, Mid. $F(1,12)=23.13, P=0.0004$, but not before, during the N350 from 300 to $400 \mathrm{~ms}, F \mathrm{~s}<2, P \mathrm{~s}>0.18$, or $400-500 \mathrm{~ms}$, Lat. $F<2.3, P>0.16$, Mid. $F<3.7$, $P>0.08$. During the LPC, condition interacted reliably with site, Lat. $F(7,84)=6.72, P=0.0001, \varepsilon=0.6506$, Mid. $F(7,84)=6.72, P=0.0001, \varepsilon=0.6506$, and hemisphere, $F(1,12)=6.62, P=0.0244$, but did not earlier from 300 to $400 \mathrm{~ms}, F \mathrm{~s}<1.5, P \mathrm{~s}>0.24$, or $400-500 \mathrm{~ms}$, $F \mathrm{~s}<2.8, P \mathrm{~s}>0.12$.

\subsubsection{Level 2 identified versus Level 5 unidentified}

ERPs to identified ascending Level 2 fragments were compared to unidentified new Level 5 fragments. Condition main effects were marginal from 300 to $400 \mathrm{~ms}$, Lat. $F(1,12)=$ 5.00, $P=0.0451$, Mid. $F(1,12)=6.18, P=0.0286$, and $400-500 \mathrm{~ms}$, Lat. $F=5.71, P=0.0342$, Mid. $F=5.27$, $P=0.0406$, and reliable from 500 to $800 \mathrm{~ms}$, Lat. $F=$ 7.74, $P=0.0166$, Mid. $F=6.89, P=0.0222$, when condition also interacted with lateral site, $F(7,84)=3.53$, $P=0.0234, \varepsilon=0.4649$.

\subsubsection{Level 2 versus Level 5: new}

Since these two contrasts confounded block (and repetition) with identification, we held condition (and repetition) constant and further tested whether the N350 to unidentified pictures was larger for new objects at Levels 5 than 2 ( $\alpha=0.05$, block source of variance for one contrast). It was (Fig. 7), Level 5 fragments had larger frontal N350s than Level 2 fragments; these differed reliably only from 300 to $400 \mathrm{~ms}$ (main block effect, Lat. $F[1,12]=5.77, P=$ 0.0333 , Mid. $F[1,12]=5.83, P=0.0327$; block $\times$ site interaction, Lat. $F[7,84]=3.48, P=0.0458$ ). Block $\times$ site interactions were also reliable from 500 to $800 \mathrm{~ms}$, Mid. $F(2,24)=5.22, P=0.0163, \varepsilon=0.7664$, when the 

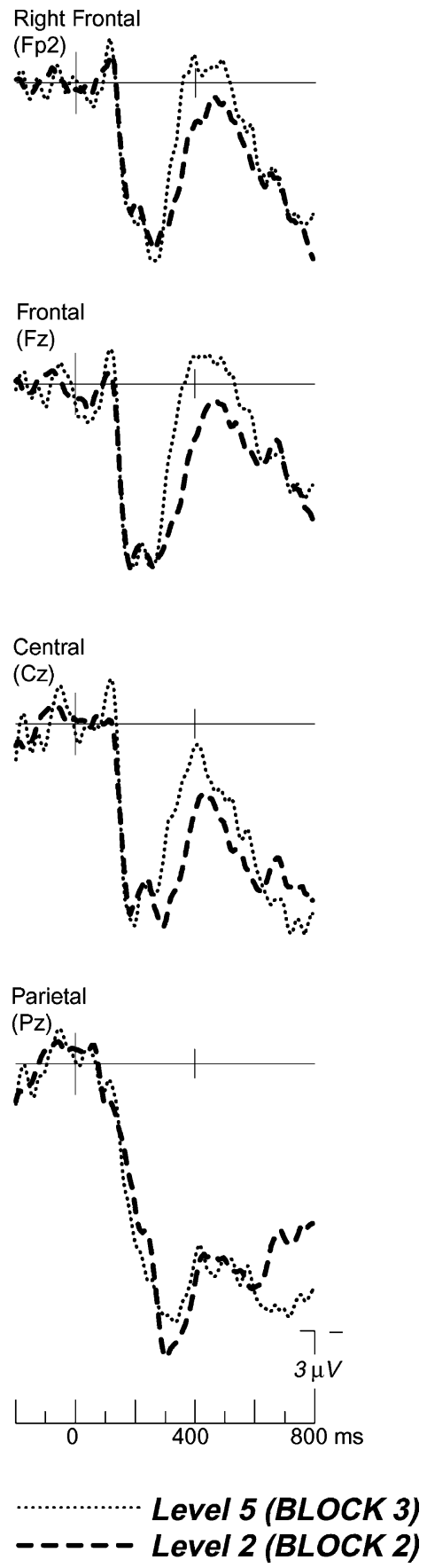

Fig. 7. Grand average ERP waveforms to unidentified objects in the new condition of Block 2 (Level 2) versus Block 3 (Level 5) fragmented pictures are shown for $800 \mathrm{~ms}$ after stimulus onset with a $200 \mathrm{~ms}$ pre-stimulus baseline (filtered low pass $40 \mathrm{~Hz}$ ). ERPs to unidentified fragments are collapsed across guess and no idea responses. The block (i.e. level or part recoverability) effect: a frontal $\mathrm{N} 350(300-400 \mathrm{~ms})$ is more negative for recoverable (Level 5) than non-recoverable (Level 2) unidentified pictures.

LPC was more positive posteriorly with Level 5 fragments (Fig. 7), perhaps due to repetition (by Block 3, "new" fragments had been seen once before in Block 2 when they were entirely novel).

\subsubsection{Scalp distribution}

An omnibus ANOVA on difference waves from Block 2 (ascending condition) and Block 3 (new condition) evaluated whether the shape of the scalp distribution of identification effects (assessing neural generators) differed between fragment types and over time (for N350 and LPC). The early N350 identification effect was measured from 300 to $400 \mathrm{~ms}$, and the late LPC identification effect from 550 to $650 \mathrm{~ms}$; note that $550 \mathrm{~ms}$ was based on the onset latency analysis of the Level 2 contrast. Indeed, the shape of the scalp distributions of the N350 versus the LPC identification difference waves differed (time $\times$ site interaction, $F[18,216]=4.81, P=0.0154)$. Neural generators of the N350 identification effects for Level 5 fragments seemed to differ from later effects with Level 5 fragments and any identification effects for Level 2 fragments: while the block $\times$ site interaction was not reliable, $F(18,216)=1.42$, $P=0.2415$, the time $\times$ block $\times$ site interaction was marginal, $F(18,216)=2.45, P=0.078$. Three contrasts further evaluated scalp distribution shape differences. First, the shape of the scalp distribution of the N350 for identification difference waves at Level 5 versus Level 2 were compared $(\alpha=0.025$, block $\times$ site interaction source of variance for the next two contrasts) and found to differ: the block $\times$ site interaction was reliable, $F(18,216)=2.58$, $P<0.001$. Second and by contrast, the block $\times$ site interaction was not reliable for this same comparison of Level 5 versus Level 2 during the LPC, $F=0.80, P>0.5$. Finally, a similar analysis suggested no difference in the neural generators of identification effects during the N350 for Level 5 fragments and the LPC for Level 2 ones $(\alpha=0.05$, block $\times$ time $\times$ electrode interaction source of variance for one contrast).

\subsection{Block 2 (Level 2)}

\subsubsection{Identification effects}

ERPs to objects in the ascending condition (Fig. 4) diverged as a function of identification for the first time during the LPC when identified objects elicited more positivity than unidentified ones $(\alpha=0.025$, identification source of variance for two contrasts). Main identification effects were reliable only from 500 to $800 \mathrm{~ms}$, Lat. $F(1,12)=11.24$, $P=0.0058$, Mid. $F(1,12)=14.35, P<0.0026$, when identification interacted reliably with lateral site, $F(7,84)=$ 5.55, $P=0.0009, \varepsilon=0.6152$, and hemisphere, $F(1,12)=$ $15.92, P=0.0018$.

3.3.1.1. Onset latency. Point-by-point $F$-tests $(500-800 \mathrm{~ms}$; $\alpha=0.025$ as for the above identification contrast) estimated the onset latency of LPC identification effects at $544 \mathrm{~ms}$ at the frontal F3 site.

3.3.1.2. Scalp distribution. The shape of the scalp distribution (assessing neural generators) of the N350 versus the 
LPC identification effects should differ if the N350 is absent at Level $2(\alpha=0.025$, time $\times$ site interaction source of variance for two contrasts). Consistent with this, the time $\times$ site interaction was marginal, $F(18,216)=3.02, P=0.0433$.

\subsubsection{Identified versus unidentified separated by re-} sponse. ERPs to identified objects were contrasted separately to unidentified pictures sorted according to whether participants made (a) "guess" responses where people said a name not on the Snodgrass and Vanderwart [53] list (\# trials: $M=14$, range 4-22) and (b) "no idea" responses where they did not know what the object was (\# trials: $M=23$, range 12-36); note that Stuss et al. [55] did not subdivide their ERPs in this way, limiting their conclusions to correct identification versus wrong guesses, as opposed to correct versus no identification. Data of two participants with too few trials were excluded (list factor dropped; $\alpha=0.0125$, half the 0.025 alpha of the identification contrast). "Guess" and "no idea" (unidentified) responses in the ascending condition yielded about the same identification times: 500-800 ms (Fig. 8). ERPs to identified versus unidentified guess responses differed only during the LPC; main identification effects were marginal at lateral sites, $F(1,13)=4.28$, $P=0.0590$, and at the midline $F(1,13)=6.91, P=$ 0.0208 , from 500 to $800 \mathrm{~ms}$ but not before $(300-500 \mathrm{~ms}$, $F \mathrm{~s}<2.1, P \mathrm{~s}>0.17)$. Importantly, ERPs to identified and unidentified no idea responses also differed reliably only during the LPC (500-800 ms: main identification effect, Lat. $F[1,13]=6.81, P=0.0216$, Mid. $F[1,13]=11.53$, $P=0.0048$; identification $\times$ site interaction, $F[7,91]=$ 4.60, $P=0.0080, \varepsilon=0.3937$; identification $\times$ hemisphere interaction, $F[1,13]=13.27, P=0.0030$ ). Thus, the delayed identification effect for Level 2 fragments was not due to any potential identification-related processes (and associated positivity) for guesses contaminating ERPs to unidentified fragments.

3.3.1.4. Repetition effects. To assess episodic LTM effects, ERPs to ascending objects were contrasted with those to new objects (\# trials: $M=56$, range 44-66), where both were unidentified (collapsed across response types) because too few new objects were identified. No repetition effects reliably affected either the N350 or LPC (Fig. 9). Main repetition effects were reliable only from 400 to $500 \mathrm{~ms}$ at the midline, $F(1,12)=6.59, P=0.0247(\alpha=0.05$, repetition source of variance for one contrast).

3.3.1.5. Identification and repetition effects. To be safe, we also analyzed unidentified new objects to which participants responded "no idea", as these were subject to neither repetition nor identification effects (\# trials: $M=35$, range 12-59). These ERPs were compared to identified ascending ones (involving both repetition and identification processes). This contrast should yield the earliest identification divergence (Fig. 10; $\alpha=0.05$, repetition $\times$ identification source of variance for one contrast). While differences did start

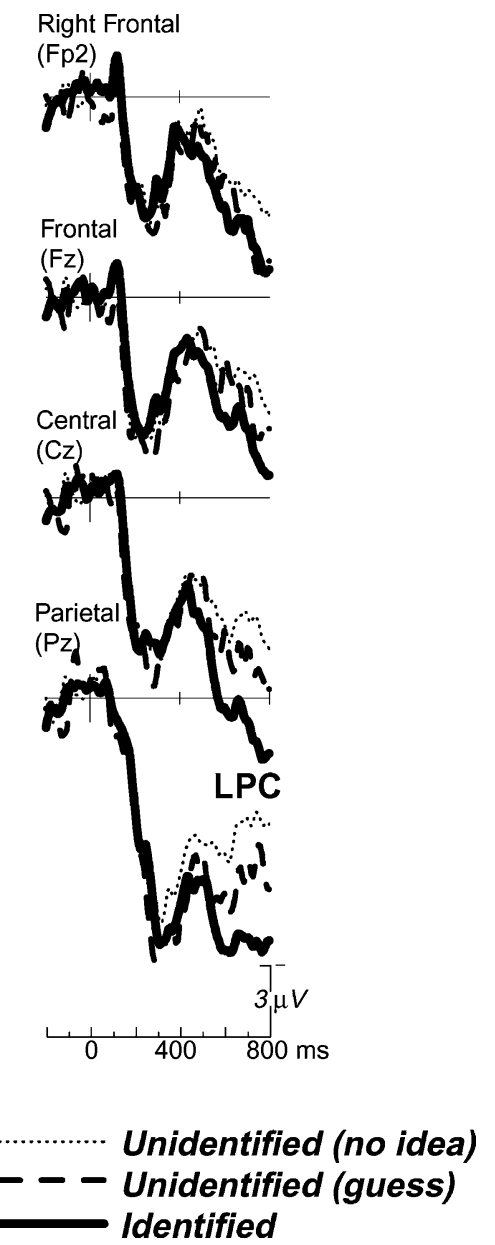

Fig. 8. Grand average ERP waveforms to identified and to unidentified objects which are shown separately for guess versus no idea responses. ERPs to fragmented pictures in Block 2 (Level 2) for the ascending condition are shown for $800 \mathrm{~ms}$ after stimulus onset with a $200 \mathrm{~ms}$ pre-stimulus baseline (filtered low pass $40 \mathrm{~Hz})$. Late $(500-800 \mathrm{~ms})$ LPC identification effects are larger, especially posteriorly, when people had no idea than when they incorrectly guessed the object's name.

earlier, they were not as early as the N350. Main identification effects were reliable from 400 to $500 \mathrm{~ms}$, Mid. $F(1,12)=4.96, P=0.0459$, and during the LPC $(500-800 \mathrm{~ms})$, Lat. $F=16.05, P<0.0017$, Mid. $F=$ $20.11, P=0.0007$, when they also interacted with lateral site, $F(7,84)=5.73, P=0.0009, \varepsilon=0.5010$, and hemisphere, $F(1,12)=6.75, P=0.0233$.

\subsection{Block 3 (Level 5)}

\subsubsection{Identification effects}

ERPs to identified and unidentified objects differed by the N350 and thereafter (Fig. 5). Main identification effects were reliable by $300-400 \mathrm{~ms}(\alpha=0.025$, identification source of variance for two contrasts), Lat. $F(1,12)=$ $6.75, P=0.0233$, Mid. $F(1,12)=7.76, P=0.0165$, and from 400 to $500 \mathrm{~ms}$, Lat. $F=14.04, P=0.0028$, Mid. 


\section{REPETITION EFFECT}

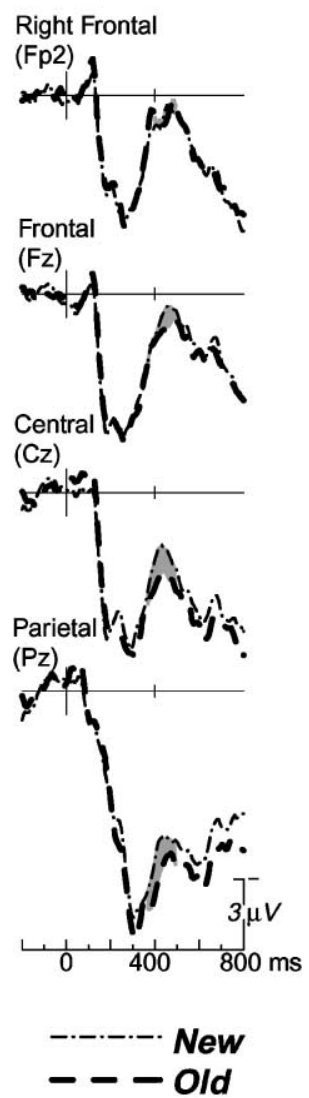

Fig. 9. Grand average ERP waveforms show repetition effects from 400 to $500 \mathrm{~ms}$ (shaded) to unidentified Level 2 objects in Block 2 (guess and no idea responses collapsed). ERPs to old pictures (repeated ascending from Block 1) and new ones are shown for $800 \mathrm{~ms}$ after stimulus onset with a $200 \mathrm{~ms}$ pre-stimulus baseline (filtered low pass $40 \mathrm{~Hz}$ ). There was more positivity to old than new fragments; note the absence of repetition effects at a frontolateral site (Fp2) where early identification effects appear in Blocks 1 and 3 (but not here in Block 2).

$F=18.83, P=0.0010$, and $500-800 \mathrm{~ms}$, Lat. $F=14.56$, $P=0.0025$, Mid. $F=18.29, P=0.0011$, when identification interacted reliably with site $\times$ hemisphere, $F(7,84)=$ 3.69, $P \mathrm{~s}=0.0103, \varepsilon=0.6092$; note that there were too few trials to analyze separately guess and no idea ERPs.

\subsubsection{Onset latency. Point-by-point $F$-tests $(300-400 \mathrm{~ms})$} estimated the earliest onset of N350 identification effects at $336 \mathrm{~ms}$ at frontal sites (Fz, F4) with $\alpha=0.025$ and at $312 \mathrm{~ms}$ with $\alpha=0.05$.

3.4.1.2. Scalp distribution. The shape of the scalp distribution of the N350 versus the LPC identification effects should differ if N350 and LPC effects index even somewhat distinct brain systems, and they do, $F(18,216)=6.28$, $P=0.0015(\alpha=0.025$, time $\times$ site interaction source of variance for two contrasts).

\section{IDENTIFICATION and REPETITION EFFECT}

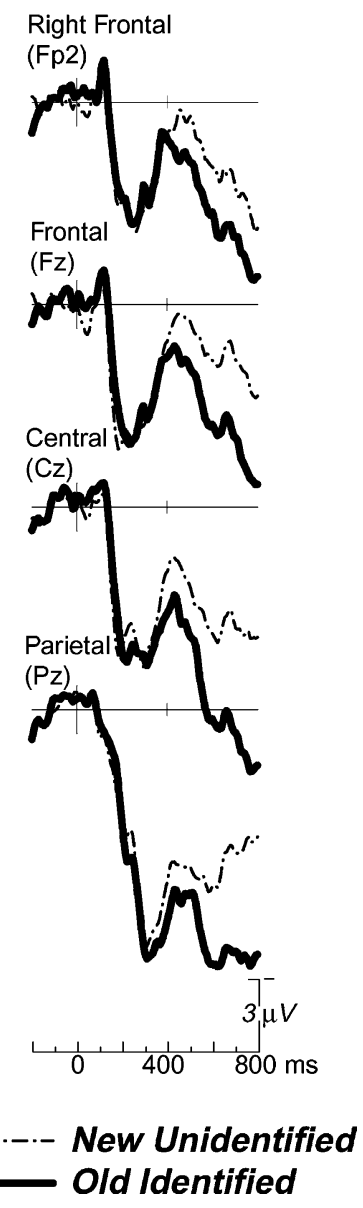

Fig. 10. Grand average ERP waveforms in Block 2 to objects that were both repeated and identified versus ERPs to objects that were both unrepeated and fully unidentified differ by $400-500 \mathrm{~ms}$. ERPs to old (ascending condition) identified and new unidentified fragments eliciting no idea responses are shown for $800 \mathrm{~ms}$ after stimulus onset with a $200 \mathrm{~ms}$ pre-stimulus baseline (filtered low pass $40 \mathrm{~Hz}$ ). LPC identification effects with non-recoverable (Level 2) pictures start somewhat earlier (400-500 ms) when ERPs to completely unidentified objects are not modulated by repetition.

\section{Discussion}

We find that stimulus factors (i.e. part recoverability), and not memory processes, explain the different latencies of visual object identification reported in two prior studies [37,55]. Specifically, we find that (a) images with recoverable parts are identified faster than ones with non-recoverable parts, and (b) the difference does not seem due merely to a shift in the latency of a single identification process. Rather, the ERP pattern implicates two partly distinct processing sequences for object identification: early identification based on search through an object selection system reflected in modulation of a frontal negativity (N350) and later identification based on top-down parsing, 
stimulus evaluation and categorization processes reflected in a broadly distributed late positivity (LPC) around $550 \mathrm{~ms}$.

\subsection{Why not memory?}

Early identification times cannot be due solely to availability of prior image information in working memory, as this would apply only to the early latencies obtained in the ascending sequence of items in Block $1(\sim 300 \mathrm{~ms})$ but not for the single items in Block $3(\sim 312-336 \mathrm{~ms})$ where such information is not in working memory. Likewise, no simple episodic LTM account can explain why Block 2 is associated with a late identification pattern and Block 3 an early identification pattern when items in both blocks were subject to episodic LTM influences by virtue of being repeated. Also ruled out is the possibility that some form of repetition positivity [42] masked the frontal N350 identification effect and spuriously delayed ERP identification latencies in Blocks 2 and 3, as the repetition positivity was too small and too late (post $400 \mathrm{~ms}$ ) to do so. In sum, then, neither working memory nor episodic LTM processes can account for the early versus late identification times previously reported and that we observed under similar conditions within the same individuals in any straightforward fashion $[37,55]$.

\subsection{Visual stimulus characteristics}

Our results indicate instead that visual stimulus characteristics are critical for determining whether an early or late identification pattern is observed. Within the same people, we found that ERP identification effects occur earlier for recoverable objects (Levels 4-5 in Block 1; Level 5 in Block 3) than for non-recoverable ones (Level 2 in Block 2). Indeed, part recoverability can explain all extant findings: Identification begins by $\sim 300 \mathrm{~ms}$ for recoverable images, landscape scenes [37] and fragmented pictures (Level 5) [62], but not until $544 \mathrm{~ms}$ for non-recoverable images, fragmented pictures (Level 2) [55].

Our findings are consistent with accounts of visual processing when object parts are recoverable versus non-recoverable (e.g. [4,9]). According to the "recognitionby-components" theory, for example naming is mediated by intermediate representations of 3D volumetric primitives called geons $[4,5]$. Geons are derived from object parts that are either easily discerned from the available contours or readily recovered by analyzing non-accidental properties in 2D images (e.g. collinearity, symmetry, edge type). Identification (object selection) occurs when the percept is matched to a higher order object model that specifies the global spatial configuration of these geons (or parts). However, when only a few intermediate geon/part representations are activated, as in the case of non-recoverable pictures, the object model selection system may not receive sufficient information to determine identity [4]. It, thus, seems reasonable to suppose that visual object identification is early when parts are visible and recoverable, and late when they are not. While we think it is the case, we must note that we cannot be entirely certain that the ERP effects reported here are due solely to recoverability of parts as our fragmented pictures were also disrupted in their more global structural configuration. The effects of part recoverability and global configuration could be teased apart by contrasting ERPs to pictures wherein the object parts are visible and the configurations are either scrambled or not [9]. ${ }^{1}$

\subsection{Identification componentry and functional significance}

While identification success is generally associated with more positivity, and identification failure with more negativity, two different ERP components - the frontal N350 and the LPC - seem to index early and late identification. The LPC $(\sim 550 \mathrm{~ms})$ is associated with later identification success for recoverable and non-recoverable pictures. In contrast, identification success is first indexed earlier for recoverable pictures by a frontal N350 that is smaller for identified than unidentified objects.

The frontal N350 probably reflects the same processes as the occipitotemporal "Ncl" (using a nose reference) that is more negative to identified fragmented pictures [13]. While the $\mathrm{Ncl}(\sim 232 \mathrm{~ms})^{2}$ has been linked to completion processes that compensate for partial visual information (i.e. perceptual closure), this seems dubious since complete pictures, for which a closure function is not needed, also modulate the frontal N350 [45,48]. Rather we propose that these components reflect object selection processes. ${ }^{3}$ The timing of this function fits well with known visual processing times: (a) the earliest (125-175 ms) effects of perceptual categorization occur $\sim 100 \mathrm{~ms}$ after striate cortex activation $(50-80 \mathrm{~ms})$ [10], and (b) this visual categorization (i.e. discriminating faces from other objects) is easier and less specific than the basic level naming that overtly reveals identification success in the present study. Hence, identification may be expected to entail $\sim 100 \mathrm{~ms}$ of further processing, estimating identification time at $\sim 275 \mathrm{~ms}$, within the $232-300 \mathrm{~ms}$ range based on the $\mathrm{Ncl} / \mathrm{N} 350$. The $\mathrm{N} 350$ is likely a subcomponent of a frontal negativity peaking $\sim 400 \mathrm{~ms}$ found previously for non-objects $[20,46]$ and related to a frontal N400 (N380, "Ny") evoked by pictures of real objects or nonsense figures $[39,48,56]$. Being larger for more complex images [39,56], the N400 was hypothesized to index access to long-term memory [56]. More specifically, Pietrowsky et al. [37] proposed that the reduction of the frontal negativity with successful identification reflects pruning of the set of possible object representations to the one matching the percept.

\footnotetext{
${ }^{1}$ Such scrambled images may also be identified without prior exposure, unlike Level 2 fragments herein.

${ }^{2} \mathrm{~N} 350 / \mathrm{Ncl}$ latencies may generally overestimate identification time because analyses that are the same for identified and unidentified objects (e.g. initial failed matching attempts) and subcortical processing cannot be detected.

${ }^{3}$ Object selection may follow or parallel image transformation $[8,58]$ or perceptual grouping processes $[23,45,63]$.
} 
We concur and propose further that the frontal N350 reflects the activity of a neural system with a pivotal role in identification: searching for a stored structural description that matches the perceived image; it is, thus, a neurophysiological marker for object model selection. Accordingly, the N350 will be small when: (a) a match or small set of matches is found as for identified, recoverable pictures (Level 5), or (b) too little information is accessible at this point in processing for any object model to match the percept, as for non-recoverable pictures (Level 2) around $300 \mathrm{~ms}$, regardless of eventual identification success. In contrast, the N350 is large whenever the visible and recoverable object parts are compatible with such a wide array of possible configurations that they impel an extensive (but ultimately unsuccessful) search through the model selection system. On this view, the large frontal N350 evoked to non-objects likewise reflects extensive but unsuccessful covert model searching and matching operations. Because non-objects cannot be consciously identified and disengagement of parieto-occipital cortex from object selection purportedly occurs at $\sim 400 \mathrm{~ms}$ (in alpha rhythm) outside of visual awareness [60], we consider the N350 to reflect covert object matching operations. In sum, the frontal N350 identification effect indicates that within $300 \mathrm{~ms}$ after seeing a well-specified image, an object model begins to be selected for further evaluation and response preparation.

LPC modulation has been linked to categorization and stimulus evaluation processes [29]. When object identification succeeds, a large LPC is elicited for both recoverable and non-recoverable images. We propose that this reflects secondary processes, such as (a) various inferential procedures purported to focus attention on and/or search for and parse parts from the contours of impoverished images [9], and (b) the activation of semantic knowledge and name(s) for all images [12]. Stuss et al. [55], likewise, suggested the LPC marks the conclusion of the perceptual evaluation of stimuli. Altogether, these data lead us to propose a dual time course model of visual object identification: recoverable images recruit object model selection operations early in the time course of processing, whereas non-recoverable images recruit model selection and other identification-related processes only later.

\subsection{Neuroanatomical considerations}

This dual time course view of object identification receives some support from the shapes of the scalp distributions (assessing overlap of neural generators) of the various identification effects. Neural generators during the N350 are partly distinct from those during the LPC for both recoverable and non-recoverable images, and, during the N350 interval, recoverable fragments engage neural generators that are partly distinct from those for non-recoverable ones. Thus (i) recoverable pictures recruit an object model selection system early on and different identification-related brain systems later, and (ii) the model selection system is recruited between 300 and $400 \mathrm{~ms}$ by recoverable images but not (or less so) by non-recoverable ones. Also, the neural systems supporting identification effects during N350 for recoverable images seem to be equivalent to those during the LPC for non-recoverable ones, congruent with our idea that the model selection system is engaged within $300 \mathrm{~ms}$ by recoverable images but only after $550 \mathrm{~ms}$ by non-recoverable ones. Finally, the brain systems underlying LPC identification effects were indistinguishable between recoverable and non-recoverable fragments; these results ${ }^{4}$ suggest that late in processing, after $550 \mathrm{~ms}$, both primary object model selection operations and secondary identification-related processes are recruited to some extent by both recoverable and non-recoverable images.

We speculate that the neuroanatomical locus of the neural processes indexed by the N350 identification effect is in occipitotemporal and mid-fusiform regions [13] implicated in shape representation and identification functions that may be consciously assessable $[12,16-18,22,24,25,28,32,38,44,49,57]$, as the related $\mathrm{Ncl}$ has been localized to these areas. Many brain regions seem to contribute to LPC effects [19], such as temporal regions linked to object knowledge and naming processes [12]. Also, lateral prefrontal and posterior parietal areas have been implicated in feedback operations that search, parse, and select additional features/parts to enable the computation of identity from impoverished images, probably by interacting with ventral object areas [24]. While our study was not designed to address awareness, the LPC may index a frontoparietal network implicated in selection of perceptual events leading to visual awareness of object identity [26,27]. Conscious identification likely entails later re-activation of the model selection system via widespread brain areas; after all, visual awareness of identity is thought to involve areas supporting object perception $[2,14,27]$.

\subsection{More functional significance}

Our account is consistent with neuropsychological data. Impaired identification of ambiguously-specified pictures has been found without impaired identification of well-specified ones [40]. Studies with amnesic patients suggest distinct processes mediate priming for fragmented versus complete pictures [61]. Finally, in our view, priming effects are smaller for less than more fragmented pictures because only the latter recruit additional processes, such as those parsing parts from non-recoverable images [51].

\section{Conclusions}

By the time the ERPs differ between identified and unidentified objects, visual image processing must have

\footnotetext{
${ }^{4}$ Null shape effects can result spuriously from too few recording sites and/or the widespread LPC scalp distribution.
} 
advanced enough to determine identity successfully and support naming. For recoverable pictures, this time is $\sim 300 \mathrm{~ms}$ and is reflected in the modulation of the frontal $\mathrm{N} 350$ as the neural system uses bottom-up processing of the perceived image to select a matching object model. When the system fails to recover any structural description, the N350 is large; when a match is achieved, both the N350 (leading to its reduction) and the subsequent LPC are more positive. For non-recoverable pictures, this time is later, and early object selection processes, indexed by the frontal $\mathrm{N} 350$, are bypassed as they do not receive sufficient input to initiate a search at this time, calling instead on top-down procedures, such as those proposed to parse and search for parts in degraded visual images. Identification, thus, is delayed by these additional processes, as reflected in the LPC ( $\sim 544 \mathrm{~ms})$.

\section{Acknowledgements}

This study was conducted in the Department of Cognitive Science and submitted in partial satisfaction of the doctoral dissertation in Cognitive Science and Neurosciences at the University of California, San Diego. Research was supported by: fellowships from the McDonnell-Pew Center for Cognitive Neuroscience in San Diego and a President's Dissertation Fellowship to H. Schendan; grants HD22614 and MH52893 to M. Kutas. We thank two anonymous reviewers for insightful suggestions for improving the manuscript.

\section{References}

[1] Allan K, Doyle MC, Rugg MD. An event-related potential study of word-stem cued recall. Cognitive Brain Research 1996;4(4):251-62.

[2] Bar M, Biederman I. Localizing the cortical region mediating visual awareness of object identity. Proceedings of the National Academy of Sciences of the United States of America 1999;96(4):1790-3.

[3] Bentin S, McCarthy G. The effects of immediate stimulus repetition on reaction time and event-related potentials in tasks of different complexity. Journal of Experimental Psychology: Learning, Memory, and Cognition 1994;20(1):130-49.

[4] Biederman I. Recognition-by-components: a theory of human image understanding. Psychological Review 1987;94(2):115-7.

[5] Biederman I. Recognition-by-components: a theory of human image understanding: clarification. Psychological Review 1989;96(1):2.

[6] Bruce V, Burton M, Carson D, Hanna E, Mason O. Repetition priming of face recognition, in Attention and performance 15: Conscious and non-conscious information processing. Attention and performance series, Cambridge (MA): MIT Press, 1994. p. 179-201.

[7] Brunas-Wagstaff J, Young AW, Ellis AW. Repetition priming follows spontaneous but not prompted recognition of familiar faces. Quarterly Journal of Experimental Psychology 1992;44A:423-54.

[8] Bülthoff HH, Edelman SY, Tarr MJ. How are three-dimensional objects represented in the brain? Cerebral Cortex 1995;5(3):247-60.

[9] Cave CB, Kosslyn SM. The role of parts and spatial relations in object identification. Perception 1993;22(2):229-48.

[10] Clark VP, Fan S, Hillyard SA. Identification of early visual evoked potential generators by retinotopic analyses. Human Brain Mapping 1995;2:170-87.
[11] Corkin S. Some relationships between global amnesias and the memory impairments in Alzheimer's disease. In: S. Corkin, editor. Alzheimer's disease: a report of progress. New York: Raven Press, 1982. p. $149-164$.

[12] Damasio H, Grabowski TJ, Tranel D, Hichwa RD, Damasio AR. A neural basis for lexical retrieval. Nature 1996;380(6574):499-505.

[13] Doninger GM, Foxe JJ, Murray MM, Higgins BA, Snodgrass JG, Schroeder CE, et al. Activation time course of ventral visual stream object-recognition areas: high density electrical mapping of perceptual closure processes. Journal of Cognitive Neuroscience 2000;12(4):615-21.

[14] Farah MJ, Feinberg TE. Consciousness of perception after brain damage. Seminars in Neurology 1997;17(2):145-52.

[15] Gollin ES. Perceptual learning of incomplete pictures. Perceptual and Motor Skills 1965;21(2):439-45.

[16] Grill-Spector K, Kushnir T, Edelman S, Avidan G, Itzchak Y, Malach R. Differential processing of objects under various viewing conditions in the human lateral occipital complex. Neuron 1999;24:187-203.

[17] Grill-Spector K, Kushnir T, Hendler T, Edelman S, Itzchak Y, Malach $\mathrm{R}$. A sequence of object-processing stages revealed by fMRI in the human occipital lobe. Human Brain Mapping 1998;6(4):316-28.

[18] Grill-Spector K, Kushnir T, Hendler T, Malach R. The dynamics of object-selective activation correlate with recognition performance in humans. Nature Neuroscience 2000;3(8):837-43.

[19] Guillem F, N'Kaoua B, Rougier A, Claverie B. Intracranial topography of event-related potentials (N400/P600) elicited during a continuous recognition memory task. Psychophysiology 1995;32(4):382-92.

[20] Holcomb PJ, McPherson WB. Event-related brain potentials reflect semantic priming in an object decision task. Brain and Cognition 1994;24(2):259-76.

[21] Humphreys GW, Bruce V. Visual cognition: computational, experimental, and neuropsychological perspectives. Hove: Lawrence Erlbaum Associates, Inc., 1989.

[22] Humphreys GW, Riddoch MJ, Price CJ. Top-down processes in object identification: evidence from experimental psychology, neuropsychology and functional anatomy. Philosophical Transactions of the Royal Society of London-Series B: Biological Sciences 1997;352(1358):1275-82.

[23] Koffka K. Principles of gestalt psychology. New York (NY) Harcourt, Brace and Company, 1935. p. 720.

[24] Kosslyn SM, Alpert NM, Thompson WL, Chabris CF, Rauch SL, Anderson AK. Identifying objects seen from different viewpoints: a PET investigation. Brain 1994;117(Part 5):1055-71.

[25] Kraut M, Hart Jr J, Soher BJ, Gordon B. Object shape processing in the visual system evaluated using functional MRI. Neurology 1997;48(5):1416-20.

[26] Lumer ED, Friston KJ, Rees G. Neural correlates of perceptual rivalry in the human brain. Science 1998;280(5371):1930-4.

[27] Lumer ED, Rees G. Covariation of activity in visual and prefrontal cortex associated with subjective visual perception. Proceedings of the National Academy of Sciences of the United States of America 1999;96(4):1669-73.

[28] Malach R, Reppas JB, Benson RR, Kwong KK, Jiang H, Kennedy WA, et al. Object-related activity revealed by functional magnetic resonance imaging in human occipital cortex. Proceedings of the National Academy of Sciences of the United States of America 1995;92(18):8135-9.

[29] McCarthy G, Donchin E. A metric for thought: a comparison of P300 latency and reaction time. Science 1981;211(4477):77-80.

[30] McCarthy G, Wood CC. Scalp distributions of event-related potentials: an ambiguity associated with analysis of variance models. Electroencephalography and Clinical Neurophysiology 1985;62(3):203-8.

[31] Milner B, Corkin S, Teuber HL. Further analysis of the hippocampal amnesic syndrome: 14-year follow-up study of H.M. Neuropsychologia 1968;6(3):215-34. 
[32] Moore CJ, Price CJ. Three distinct ventral occipitotemporal regions for reading and object naming. Neuroimage 1999;10(2):181-92.

[33] Nielsen-Bohlman L, Knight RT. Electrophysiological dissociation of rapid memory mechanisms in humans. NeuroReport 1994;5(12):1517-21.

[34] Paller KA, Kutas M. Brain potentials during memory retrieval provide neurophysiological support for the distinction between conscious recollection and priming. Journal of Cognitive Neuroscience 1992;4(4):375-91.

[35] Paller KA, Kutas M, McIsaac HK. Monitoring conscious recollection via the electrical activity of the brain. Psychological Science 1995;6(2):107-11.

[36] Picton TW, Bentin S, Berg P, Donchin E, Hillyard SA, Johnson $\mathrm{R}$, Jr., et al. Guidelines for using human event-related potentials to study cognition: recording standards and publication criteria. Psychophysiology 2000;37(2):127-52.

[37] Pietrowsky R, Kuhmann W, Krug R, Molle M, Fehm HL, Born J. Event-related brain potentials during identification of tachistoscopically presented pictures. Brain and Cognition 1996;32(3):416-28.

[38] Price CJ, Moore CJ, Humphreys GW, Frackowiak RS, Friston KJ. The neural regions sustaining object recognition and naming. Proceedings of the Royal Society of London-Series B: Biological Sciences 1996;263(1376):1501-7.

[39] Ruchkin DS, Johnson R, Canoune H, Ritter W. Event-related potentials during arithmetic and mental rotation. Electroencephalography and Clinical Neurophysiology 1991;79(6):473-87.

[40] Rudge P, Warrington EK. Selective impairment of memory and visual perception in splenial tumours. Brain 1991;114:349-60.

[41] Rugg MD. Dissociation of semantic priming, word and non-word repetition effects by event-related potentials. Quarterly Journal of Experimental Psychology: Human Experimental Psychology 1987;39(1-A):123-48.

[42] Rugg MD, Doyle MC. Event-related potentials and stimulus repetition in direct and indirect tests of memory. In: Heinze H-J, Münte T-F, Mangun GR, editors. Cognitive electrophysiology. Boston: Birkhaüser, 1994. p. 125-48.

[43] Schacter DL. Priming and multiple memory system: perceptual mechanisms of implicit memory. In: Memory systems. Cambridge (MA): MIT Press, 1994. p. 233-68.

[44] Schacter DL, Reiman E, Uecker A, Polster MR, Yun LS, Cooper LA. Brain regions associated with retrieval of structurally coherent visual information. Nature 1995;376(6541):587-90.

[45] Schendan HE. The time course of activation of the neural operations and representations supporting visual object identification and memory. Doctoral dissertation, 1998 (UMI Microform No. 9820868).

[46] Schendan HE, Ganis G, Kutas M. Neurophysiological evidence for visual perceptual categorization of words and faces within $150 \mathrm{~ms}$. Psychophysiology 1998;35:240-51.
[47] Schendan HE, Kanwisher NG, Kutas M. Early brain potentials link repetition blindness, priming, and novelty detection. NeuroReport 1997;8(8):1943-8.

[48] Schendan HE, Kutas M. Time course of component processes and representations underlying visual object identification and memory, in preparation.

[49] Sergent J, Ohta S, MacDonald B. Functional neuroanatomy of face and object processing. Brain 1992;115:15-36.

[50] Snodgrass JG, Corwin J. Perceptual identification thresholds for 150 fragmented pictures from the Snodgrass and Vanderwart picture set. Perceptual and Motor Skills 1988;67(1):3-36.

[51] Snodgrass JG, Feenan K. Priming effects in picture fragment completion: support for the perceptual closure hypothesis. Journal of Experimental Psychology: General 1990;119(3):276-96.

[52] Snodgrass JG, Smith B, Feenan K, Corwin J. Fragmenting pictures on the Apple Macintosh computer for experimental and clinical applications. Behavior Research Methods, Instruments, and Computers 1987;19(2):270-4.

[53] Snodgrass JG, Vanderwart M. A standardized set of 260 pictures: norms for name agreement, image agreement, familiarity, and visual complexity. Journal of Experimental Psychology: Human Learning and Memory 1980;6(2):174-215.

[54] Srebro R. A bootstrap method to compare the shapes of two scalp fields. Electroencephalography and Clinical Neurophysiology 1996;100(1):25-32.

[55] Stuss DT, Picton TW, Cerri AM, Leech EE, Stethem LL. Perceptual closure and object identification: electrophysiological responses to incomplete pictures. Brain and Cognition 1992;19(2):253-66.

[56] Stuss DT, Sarazin FF, Leech EE, Picton TW. Event-related potentials during naming and mental rotation. Electroencephalography and Clinical Neurophysiology 1983;56(2):133-46.

[57] Tranel D, Damasio H, Damasio AR. A neural basis for the retrieval of conceptual knowledge. Neuropsychologia 1997;35(10):1319-27.

[58] Ullman S. Sequence seeking and counter streams: a computational model for bidirectional information flow in the visual cortex. Cerebral Cortex 1995;5(1):1-11.

[59] Ullman S. High-level vision: object recognition and visual cognition. Cambridge (MA): MIT Press, 1996. p. 412.

[60] Vanni S, Revonsuo A, Hari R. Modulation of the parieto-occipital alpha rhythm during object detection. Journal of Neuroscience 1997;17(18):7141-7.

[61] Verfaellie M, Gabrieli JDE, Vaidya CJ, Croce P, et al. Implicit memory for pictures in amnesia: role of etiology and priming task. Neuropsychology 1996;10(4):517-37.

[62] Viggiano MP, Kutas M. Overt and covert identification of fragmented objects inferred from performance and electrophysiological measures. Journal of Experimental Psychology: General 2000;129(1):107-25.

[63] Wertheimer M. Untersuchungen zur Lehre von der Gestalt. Psychologische Forschung 1923;4:301-50. 